\section{Identification of Citrus Chimeras by RAPD Markers}

\author{
Kuniaki Sugawara and Atsushi Oowada \\ Ehime Citrus Research Institute, Anjoji, Matsuyama, Ehime 791, Japan
}

\section{Takaya Moriguchi ${ }^{1}$ and Mitsuo Omura}

Fruit Tree Research Station, Okitsu Branch, Okitsu, Shimizu, Shizuoka 42402, Japan

Additional index words. PCR

\begin{abstract}
Random amplified polymorphic DNA (RAPD) markers were used to detect chimerism of citrus cultivars. Polymerase chain reaction conditions suitable for discriminating citrus chimeras were determined. Primers that produced consistent and repeatable bands that differed between the parental cultivars were chosen to create discriminating band patterns. Our results show that selected 12-mer primers can be useful for identifying the four citrus chimeras tested using RAPD technology.
\end{abstract}

Periclinal chimeras of citrus have been developed as a possible breeding method to improve disease resistance by combining two cultivars (Kuhara, 1988). In citrus fruit, the juice sac and pericarp epidermis originate from the outer layer of most growing points (histogenic layer I). Histogenic layer II ordinarily produces seeds, segment walls, the hypoderm, and the mesocarp of pericarp, and histogenic layer III develops into the vascular bundle (Frost and Krug, 1942). The citrus bacterial canker pathogen [Xanthomonas campestris pv.citri (Hasse) Dye] affects mainly the hypoderm and outer mesocarp of the fruit (layers II and III); citrus tristeza virus affects only cells in the phloem of vascular bundles (layer III) (Ohtsu and Kuhara, 1994). Accordingly, periclinal chimeras of citrus that are composed of layer II and III tissues, originating from a genotype resistant to citrus tristeza, and of the layer I tissue from a genotype having high fresh-fruit quality are desirable. Kuhara (1989) first produced periclinal chimeras composed of 'Fukuhara' orange [Citrus sinensis (L.) Osbeck] and 'Kawano natsudaidai' (C. natsudaidai Hayata). Periclinal chimeras were produced by approach-grafting (inarching) etiolated hypocotyls from nucellar embryos of 'Fukuhara' and 'Kawano natsudaidai' and then cutting the grafted region horizontally to induce calli. The regenerated adventitious buds from the calli were assumed to be the candidates of chimeras.

In studies of chimerism, the ability to identify both parental cultivars is indispensable. For discrimination among citrus cultivars, gas chromatography analysis of leaf oil (Ikeda, 1976), qualitative analysis of flavanones

Received for publication 30 Jan. 1995. Accepted for publication 31 May 1995. Contribution no. B-209 of the Fruit Tree Research Station. The cost of publishing this paper was defrayed in part by the payment of page charges. Under postal regulations, this paper therefore must be hereby marked advertisement solely to indicate this fact.

${ }^{1}$ To whom reprint requests should be addressed.
(Albach and Redman, 1969; Nishiura et al., 1969, 1971), high performance liquid chromatograph analysis of flavanone glycosides (Ohtsu and Kuhara, 1994), and isoenzyme analysis (Ueno, 1976) have been reported. However, such analyses cannot be used for plants in which the markers are common or similar between the parents.

DNA markers are used widely to understand the genetic relationships among organisms at the molecular level. More recently, a rapid and sensitive technique based on the polymerase chain reaction (PCR) has been introduced (Welsh and McClelland, 1990; Williams et al., 1990). PCR-based markers have been used to discriminate citrus cultivars and species (Deng et al., 1995; Omura et al., 1993). In our study, we report discrimination of citrus periclinal chimeras using random amplified polymorphic DNA (RAPD) markers.

\section{Materials and Methods}

The cultivars used in this study are listed in Table 1. FN-1 and NF-3 (Ohtsu and Kuhara, 1994) are periclinal chimeras produced by grafting. Ohtsu and Kuhara (1994) reported the production and selection of citrus chimera clones. 'Kobayashimikan' (Citrus natsudaidai and $C$. unshiu) and 'Kinkoji unshiu' $(C$. obovoidea and C. unshiu) are naturally occurring periclinal chimeras that consist of two citrus cultivars (Tanaka, 1980). Because the specific clones of satsuma mandarin (Unshiu) (C. unshiu) that contributed to the parentage of the naturally occurring periclinal chimeras ('Kobayashimikan' and 'Kinkoji unshiu') are unknown, we used the Nagashima clone of Unshiu. We consider this clone to be the original Unshiu cultivar.

Citrus leaves, immediately frozen in liquid $\mathrm{N}$, were used for DNA extraction according to Dellaporta et al. (1983). A total of 124 primers (12 nucleotides long) (Common's A, B, and C series; Bex Co., Tokyo) were investigated for RAPD analysis. PCR was performed in a total volume of $12.5 \mu \mathrm{l}$ reaction medium that contained $10 \mathrm{ng}$ citrus DNA, $10.5 \mathrm{ng}$ primers (obtained from Bex Co.), $160 \mu \mathrm{M}$ each deoxyribonucleotide triphosphate (dATP, dGTP, dCTP, and dTTP), $10 \mathrm{~mm}$ Tris- $\mathrm{HCl}$ (pH 8.9), $1.5 \mathrm{~mm} \mathrm{MgCl}_{2}, 80 \mathrm{~mm} \mathrm{KCl}, 500 \mu \mathrm{g} \mathrm{BSA} / \mathrm{ml}$, $0.1 \%$ sodium cholate, $0.1 \%$ Triton $\mathrm{X}-100$, and 0.5 units Tth DNA polymerase (Toyobo Co., Osaka, Japan). Amplification was carried out for 40 cycles, each consisting of $93 \mathrm{C}$ for $1 \mathrm{~min}$, $42 \mathrm{C}$ for $1 \mathrm{~min}$, and $72 \mathrm{C}$ for $2 \mathrm{~min}$. For evaluation of stability of generated bands, concentrations of template DNA were varied from one-fifth to five times the standard. Products were analyzed by electrophoresis in $1.5 \%$ agarose gels and were visualized by photographing under illumination of ultraviolet rays after staining with ethidium bromide.

\section{Results and Discussion}

Of 124 primers examined, 12 primers (Table 2) exhibited stable and repeatable polymorphisms among the citrus cultivars listed in Table 1 . These polymorphisms were considered to be stable and repeatable because the bands were consistent among several DNA extractions (data not shown). Because primer C-64 produced clear polymorphisms among the parental cultivars of periclinal chimeras,

Table 1. Type of plant material used.

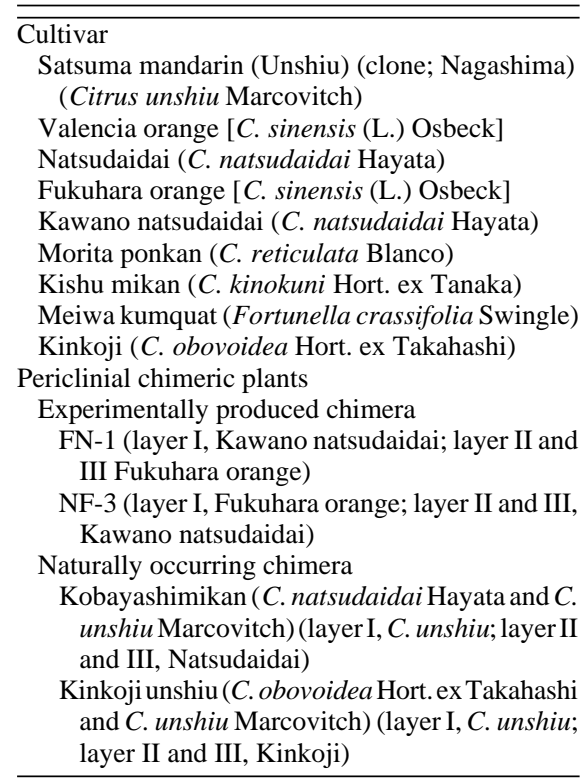

Table 2. Synthetic deoxyribonucleotide primers that revealed stable and repeatable polymorphisms among the Citrus cultivars listed in Table 1.

\begin{tabular}{lc}
\hline \hline Primer & $\begin{array}{c}\text { Nucleotide } \\
\text { sequence }\left(5^{\prime} \text { to } 3^{\prime}\right)\end{array}$ \\
\hline A-00 & ATCAGCGCACCA \\
A-19 & AAGGCGCGAACG \\
B-04 & CGCTTCGTAGCA \\
B-39 & GAGCTCCCGACA \\
B-41 & GACAGCGTCCTA \\
B-73 & TGCCCACTACGG \\
C-11 & AGGTACGCCCGA \\
C-31 & GAGTTGCCCGGA \\
C-64 & CCAGATCCGAAT \\
C-82 & ATCGTCACCCCG \\
C-88 & ATCATCGTGGGG \\
C-89 & TCCCACGTTTGG \\
\hline
\end{tabular}




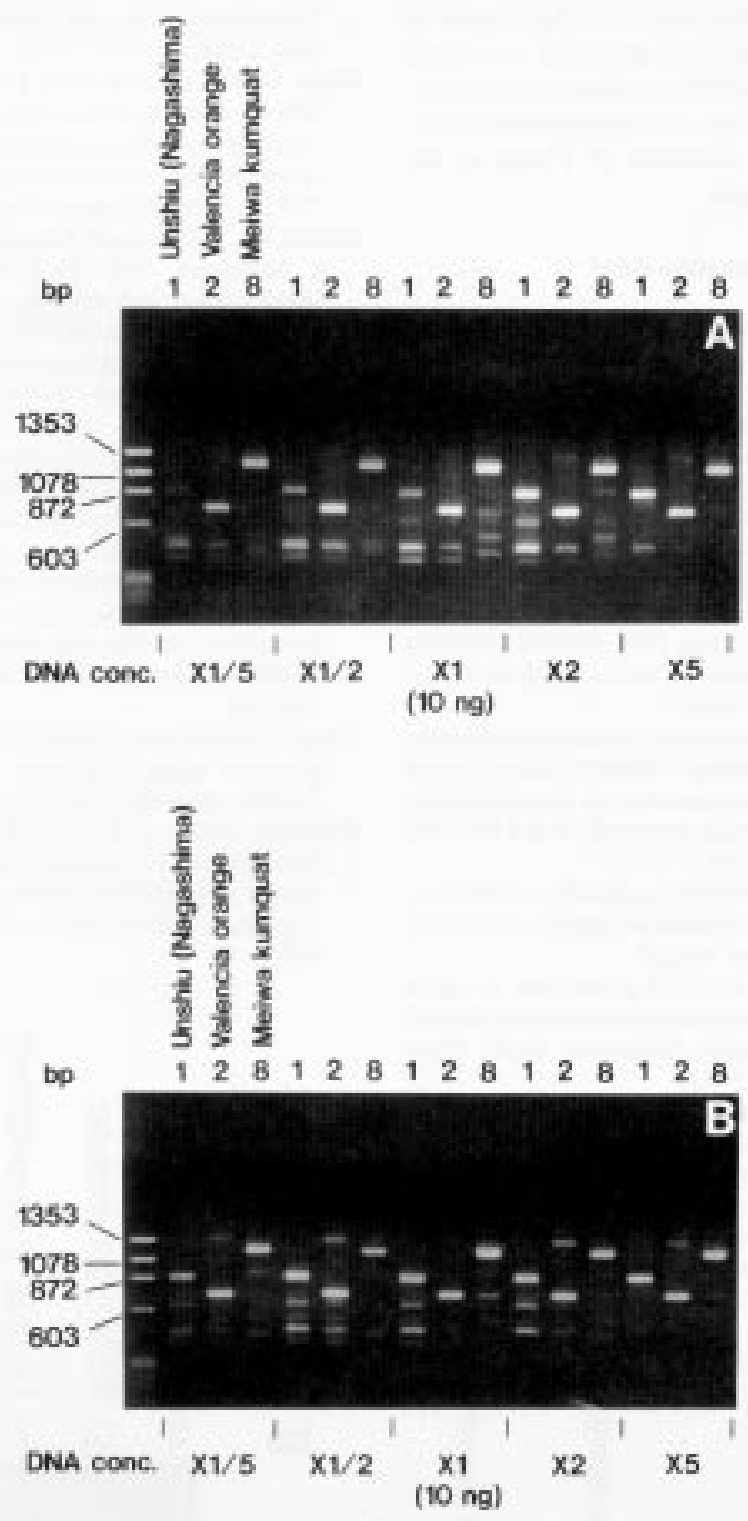

Fig. 1. Effects of DNA concentration and annealing temperature on polymerase chain reaction (PCR) patterns using primer C-64. Lanes: 1 = Unshiu, 2 = 'Valencia' orange, 3 = 'Meiwa' kumquat. (A) 42C and (B) 38C. Markers are ØX174/Hae III digest. further detailed conditions for PCR were investigated with this primer. To evaluate the effects of varying template DNA concentration and annealing temperature on the ability of primer C-64 to differentiate the parental cultivars, the template DNA concentration was varied from 2 to $50 \mathrm{ng} / 12.5 \mu \mathrm{l}$ reaction medium and was annealed at 38 and $42 \mathrm{C}$. Although some faint bands were difficult to detect with a template DNA concentration of one-fifth the standard (10 ng), the strongly amplified polymorphic bands were consistent throughout the range of template DNA concentrations (Fig. 1); therefore, we considered them to be stable markers.

Periclinal chimeras consist of cells derived from two cultivars that are arranged in various combinations of cell layers so that tissues and organs vary in the proportion of cells derived from each parent. To evaluate the ability of selected primers to detect cells derived from both parents in various tissues of a chimera, RAPD analysis was performed using template DNA prepared by mixing DNA from the two parental genotypes in ratios of $1: 9,5: 5$, and $9: 1$, holding total template DNA concentration constant. The distinct polymorphisms were detected even when the ratio of template DNA from one cultivar was $10 \%$ and $90 \%$ from the second one (Fig. 2). Primer C-64 detected the polymorphic bands in template mixtures of Unshiu (Nagashima) and 'Valencia' orange, or those of 'Valencia' and 'Meiwa' kumquat. The primer C-11 also was effective for discrimination in the combinations of 'Valencia' orange and 'Morita ponkan', or those of 'Valencia' and 'Kishu mikan'. The results predict that RAPD markers are of practical use for identifying citrus chimeras that originate from these cultivars.

Next, the selected RAPD bands were tested for their reliability in identifying actual chimeras. A set of nine cultivars, including chimeras and their parents, was subjected to PCR amplification using several synthetic primers. The chimeras FN-1 and NF-3 consist of 'Fukuhara' orange and 'Kawano natsudaidai'

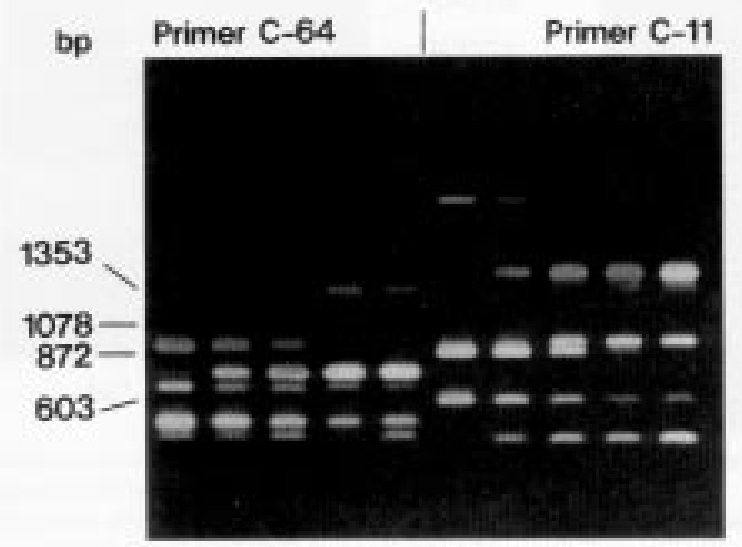

A B C D E F G H I J

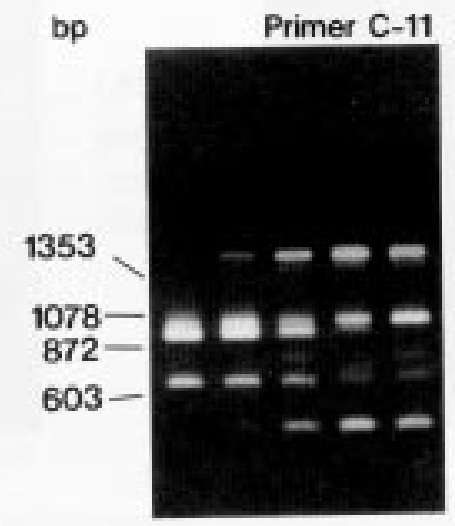

K L M N

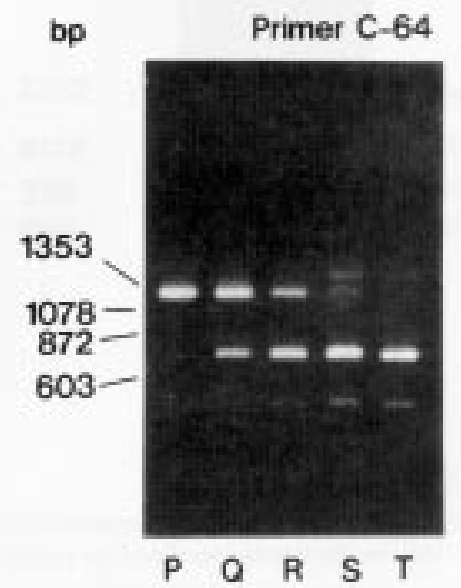

Fig. 2. PCR patterns amplified from DNA templates prepared by mixing DNA from two cultivars in various ratios. Lanes: (A) Unshiu (Nagashima) : 'Valencia' orange $=10: 0$, (B) $9: 1$, (C) $5: 5$, (D) $1: 9$, and (E) $0: 10$; (F) 'Morita ponkan': 'Valencia' orange = 10:0, (G) $9: 1$, (H) $5: 5$, (I) $1: 9$, and (J) $0: 10 ;$ (K) 'Kishu mikan': 'Valencia' orange = $10: 0$, (L) $9: 1$, (M) $5: 5$, (N) $1: 9$, and (O) $0: 10$; and (P) 'Kinkoji' : 'Valencia' orange = 10:0, (Q) $9: 1,(\mathrm{R}) 5: 5$, (S) $1: 9,(\mathrm{~T}) 0: 10$. Markers are $\varnothing \mathrm{X} 174 / \mathrm{Hae} \mathrm{III}$ digest. 
(see Table 1). Genetic identity of FN-1 was determined using primer $\mathrm{C}-89$, which amplified bands derived from 'Fukuhara' orange and 'Kawano natsudaidai' (Fig. 3). After amplification with primer C-64, chimera NF-3 showed the bands characteristic of 'Fukuhara' orange and 'Kawano natsudaidai' (Fig. 3). Not only primer C-64 but also primer A-19 was effective in determining the genetic identity of chimera NF-3 (Fig. 3).

The naturally occurring periclinal chimeras 'Kobayashimikan' and 'Kinkoji unshiu' were discriminated from each parent by amplification with primer B-04 (Fig. 4). Chimeric origins of these genotypes also were confirmed by amplifications with primer B-39 for 'Kobayashimikan' and by primers A-00 and C-11 for 'Kinkoji unshiu' (data not shown). In some cases, primers that failed to reveal bands derived from both parents mainly showed the band patterns of the parent that constructed layers II and III. This result probably is due to low yields of DNA from layer I, because it was limited to only the outer surface of the leaves from which the DNA was extracted.

We have shown that RAPD analysis can detect the chimerisms that had been confirmed in well-known chimeras, such as 'Kobayashimikan', 'Kinkoji unshiu', FN-1, and NF-3. However, RAPD band patterns did not differentiate between a chimera and a hybrid when the template DNA was extracted from a mixture of cell layers. Proof chimerism could be obtained with this method if DNA were extracted from separate cell layers. Differentiating between chimeras and hybrids is not an issue for experimentally produced chi- meras, such as FN-1 and NF-3, but it may be important for suspected naturally occurring chimeras. Thus, RAPD analysis provides useful selectable markers for experimentally produced periclinal chimeras of Citrus at the young plantlet stage.

\section{Literature Cited}

Albach, R.F. and G.H. Redman. 1969. Composition and inheritance of flavanones in citrus fruit. Phytochemistry 8:127-143.

Dellaporta, S.L., J. Wood, and J.B. Hicks. 1983. A plant DNA minipreparation: version II. Plant Mol. Biol. Rpt. 1:19-21.

Deng, Z.N., A. Gentile, E. Nicolosi, F. Domina, A. Vardi, and E. Tribulato. 1995. Identification of in vitro and in vivo lemon mutants by RAPD markers. J. Hort. Sci. 70:117-125.

Frost, H.B. and C.A. Krug. 1942. Diploid-tetraploid periclinal chimeras as bud variants in citrus. Genetics 27:619-634.

Ikeda, I. 1976. Studies on the application of essential oils in citrus breeding. I. Identification of hybrid and nucellar citrus seedlings by gas chromatography of leaf oils (in Japanese). Bul. Fruit Tree Res. Sta. E1:11-36.

Kuhara, S. 1988. Artificial production of the synthetic periclinal chimera in citrus (in Japanese). Kyushu Agr. Res. 50:222.

Kuhara, S. 1989. Artificial production of citrus periclinal chimera and disease resistance of these plants (in Japanese). Shokubutsu Boeki (Plant Protection) 43:25-29.

Nishiura, M., S. Esaki, and S. Kamiya. 1969. Flavonoids in citrus and related genera. Part I. Distribution of flavonoid glycosides in Citrus and Poncirus. Agr. Biol. Chem. 33:1109-1118.

Nishiura, M., S. Kamiya, and S. Esaki. 1971. Flavonoids in citrus and related genera. Part III.
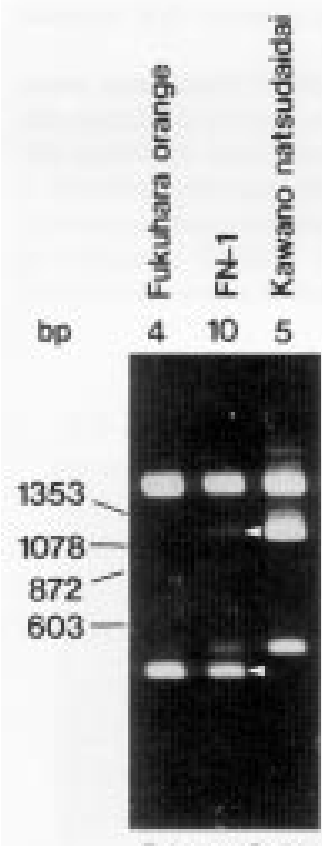

Primer $\mathrm{C}-89$

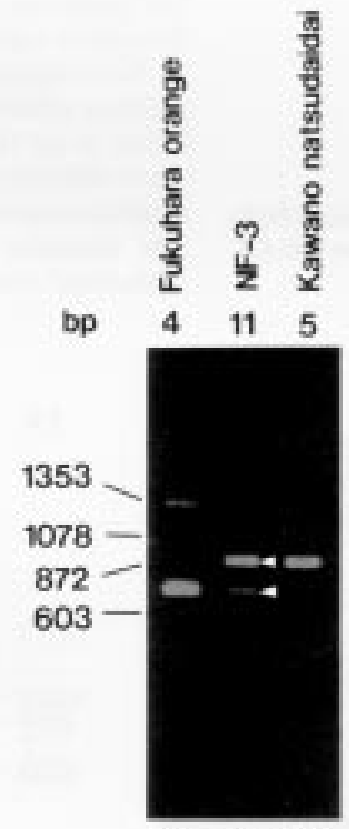

Primer C-64

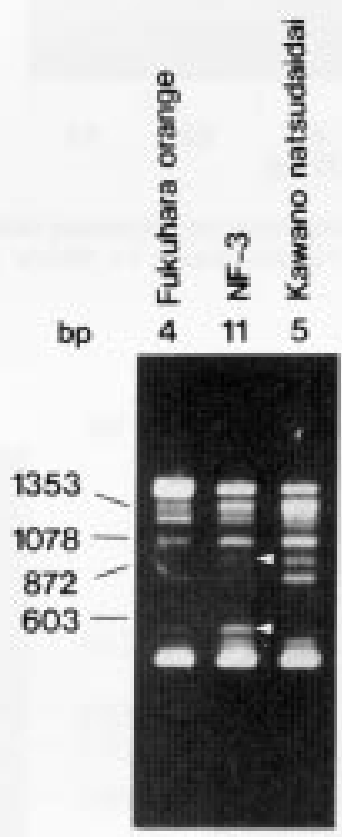

Primer A-19

Fig. 3. Amplified DNA polymorphisms of experimentally produced chimeras and their parents. Arrows indicate the bands specific to the parents. Markers are $\varnothing$ X174/HaeIII digest.

Flavonoid pattern and citrus taxonomy. Agr. Biol. Chem. 35:1691-1706.

Ohtsu, Y. and S. Kuhara. 1994. Periclinal chimera of citrus resistant to citrus canker and citrus tristeza virus: Chimerism and composition of fruit tissue in the synthetic periclinal chimeras ' $\mathrm{FN}-1$ ' and 'NF-3'. Ann. Phytopath. Soc. Jpn. 60:20-26.

Omura, M., T. Hidaka, H. Nesumi, T. Yoshida, and I. Nakamura. 1993. PCR markers for citrus identification and mapping, p. 66-73. In: T. Hayashi, M. Omura, and N.S. Scott (eds.). Techniques on gene diagnosis and breeding in fruit trees. Fruit Tree Research Sta., Tsukuba Ibaraki, Japan.

Tanaka, Y. 1980. An iconograph of Japanese citrus fruits. A monographic study of species and varieties of citrus fruits grown in Japan. vol. III. Yokendo Co., Tokyo.

Ueno, I. 1976. Application of zymography to citrus breeding II. Variations in peroxidase isozymes for species, varieties and strains of citrus and its relatives (in Japanese). Bul. Fruit Tree Res. Sta. B3:9-24.

Welsh, J. and M. McClelland. 1990. Fingerprinting genomes using PCR with arbitrary primers. Nucleic Acids Res. 18:7213-7218.

Williams, J.G.K., A.R. Kubelik, K.J. Livak, J.A. Rafalski, and S.V. Tingey.1990. DNA polymorphisms amplified by arbitrary primers are useful as genetic markers. Nucleic Acids Res. 18:65316535 .

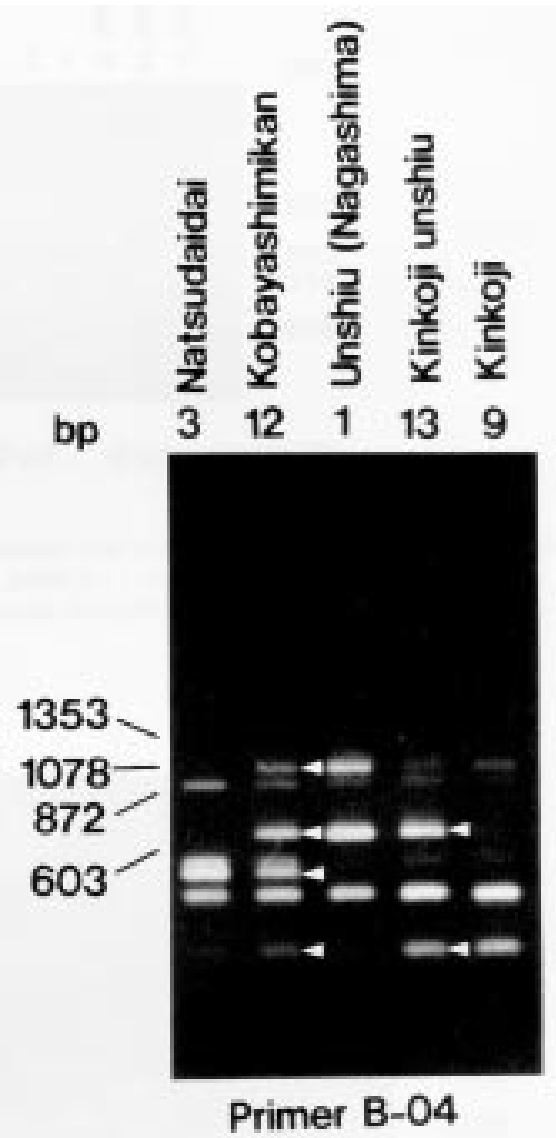

Fig. 4. Amplified DNA polymorphisms of naturally occurring periclinal chimeras and their parents. Arrows indicate the bands specific to the parents. Markers are ØX174/HaeIII digest. 